
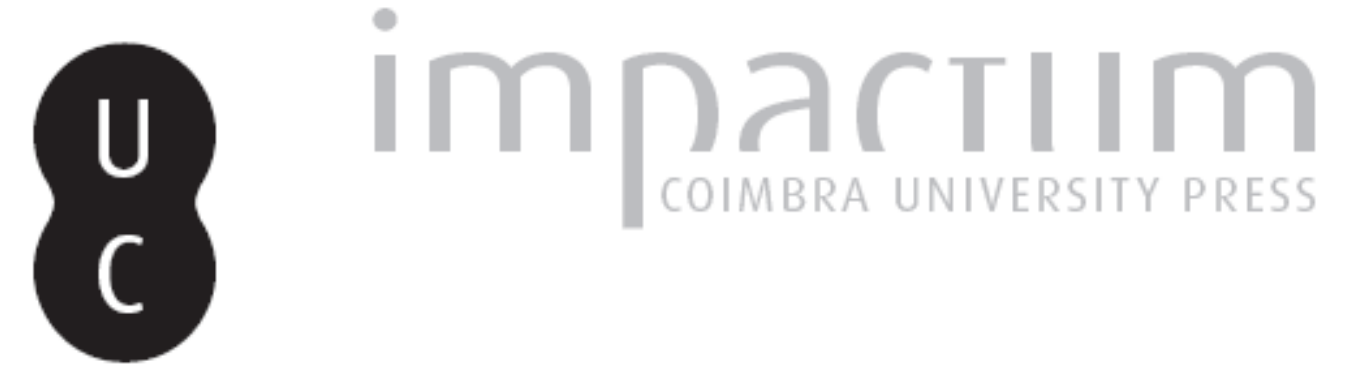

\title{
Algunos aspectos de la fenomenología de Marc Richir
}

\section{Autor(es): $\quad$ Posada Varela, Pablo}
Publicado por: Faculdade de Letras da Universidade de Coimbra, Instituto de Estudos Filosóficos

Persistente: URI:http://hdl.handle.net/10316.2/35586

DOI: $\quad$ DOI:http://dx.doi.org/10.14195/0872-0851_46_7

Accessed : $\quad$ 26-Apr-2023 15:02:40

A navegação consulta e descarregamento dos títulos inseridos nas Bibliotecas Digitais UC Digitalis, UC Pombalina e UC Impactum, pressupõem a aceitação plena e sem reservas dos Termos e Condições de Uso destas Bibliotecas Digitais, disponíveis em https://digitalis.uc.pt/pt-pt/termos.

Conforme exposto nos referidos Termos e Condições de Uso, o descarregamento de títulos de acesso restrito requer uma licença válida de autorização devendo o utilizador aceder ao(s) documento(s) a partir de um endereço de IP da instituição detentora da supramencionada licença.

Ao utilizador é apenas permitido o descarregamento para uso pessoal, pelo que o emprego do(s) título(s) descarregado(s) para outro fim, designadamente comercial, carece de autorização do respetivo autor ou editor da obra.

Na medida em que todas as obras da UC Digitalis se encontram protegidas pelo Código do Direito de Autor e Direitos Conexos e demais legislação aplicável, toda a cópia, parcial ou total, deste documento, nos casos em que é legalmente admitida, deverá conter ou fazer-se acompanhar por este aviso.






\section{REVISTA FILOSÓFICA DE COIMBRA}

vol. 23 - número 46 - outubro 2014

vol. 23 - número 46 - outubro 2014

Fundação Eng. António de Almeida






\section{ALGUNOS ASPECTOS DE LA FENOMENOLOGÍA DE MARC RICHIR}

PABLO POSADA VARELA*

Résumé: Cet article prétend valoir comme une introduction à la phénoménologie de Marc Richir. À cet effet, on commence par faire quelques allusions à son parcours intellectuel. Ensuite, nous explicitons certains de ses concepts basiques en nous appuyant sur la problématique du phénomène de langage. Enfin, nous tentons de mettre en lumière le sens du projet richirien d'un élargissement architectonique de la phénoménologie.

Mots-clefs: rien que phénomène, phénomène de langage, phase de présence, schématisme, architectonique, ipse du sens, transpassibilité, proto-spatialisation, concrétudes, affectivité, phantasia, phantasia perceptive, Marc Richir.

Resumen: Este artículo busca introducir a la fenomenología de Marc Richir. Para ello, empezamos por algunas alusiones a su recorrido intelectual. Explicitamos, más adelante, algunos de sus conceptos básicos, basándonos en la problemática del fenómeno de lenguaje. Terminamos poniendo de manifiesto el sentido del proyecto richiriano de una ampliación arquitectónica de la fenomenología.

* Université de Paris - Sorbonne (Paris IV). Bergische Universität Wuppertal; pabloposadavarela@gmail.com.

Estas páginas hallaron su primera expresión en dos conferencias impartidas en la Universidad de Coimbra gracias a la amable invitación del profesor Luís António Umbelino. La primera en noviembre de 2013 (de cuyo título toma el suyo el presente artículo, en homenaje a aquella ocasión, de tan grato recuerdo, como lo han venido siendo mis ulteriores visitas a Coimbra y a su Universidad). La segunda intervención, base también para este texto, tuvo lugar en marzo de 2014, en el contexto de un seminario de filosofía en torno a la obra de Marc Richir, impartido por el propio Marc Richir (los días 2, 3 y 4 de Abril de 2014) y precedido de un Workshop internacional dedicado a su trabajo. Una vez más expreso mi más profundo agradecimiento tanto a la Unversidad de Coimbra y a su departamento de filosofía, como al profesor Luís A. Umbelino. 
Palabras clave: nada sino fenómeno, fenómeno de lenguaje, fase de presencia, esquematismo, arquitectónica, ipse del sentido, transpasibilidad, proto-espacialización, concretudes, afectividad, phantasia, phantasia perceptiva, Marc Richir.

El propósito de estas páginas no es otro que el de introducir a algunos conceptos fundamentales de la fenomenología de Marc Richir. Como se verá, lo que Richir llama "fenómeno de lenguaje" será nuestra puerta de entrada fundamental. Evidentemente, muchas otras hay (la phantasia, la intersubjetividad, la cuestión del método y la llamada "epojé fenomenológica hiperbólica", junto con su correlativa "reducción arquitectónica", pero también la afectividad o las diversas instituciones simbólicas) ${ }^{1}$. La posibilidad de una multiplicidad de accesos es tanto más fehaciente por cuanto no nos hallamos, en el caso de Richir, ante una obra sistemática. Ahora bien, quien dice, en este caso, pluralidad, no está alegando, con ello, arbitrariedad o mera rapsodia. Que la obra de Richir nada tenga de un sistema cerrado no significa que no sea una arquitectónica organizada. Se trata, con todo, de una arquitectónica de aperturas infinitas, o, mejor dicho, de aperturas indefinidas sobre lo infinito, y donde la finitud fenomenologizante estriba, precisamente, en no poder fijar esa indefinición del acceso, en no saber dónde, hasta dónde o hasta qué punto somos, de veras, finitos.

Al correr de los años, la fenomenología de Richir ha terminado tomando la forma de una arquitectónica de los problemas, una suerte de tópica y topología de las aporías. Cada problema tiene su residencia arquitectónica o, como suele ser el caso, se expande y muerde sobre varios registros de fenomenalizaicón. La aporética de la intersubjetividad, por ejemplo, moviliza elementos de registros varios (de la phantasia, de la imaginación, de la percepción). Por eso, cada punto de entrada es una travesía que ilumina ciertas regiones e, inevitablemente, deja otras en la penumbra. Con todo, la entrada por el fenómeno de lenguaje nos parece tener la virtud de cubrir un amplio espectro de la problemática richiriana.

${ }^{1}$ A este respecto cumple hacer mención a la extraordinaria página web creada por Sacha Carlson, ineludible e impagable fuente de información para todo aquel que se ocupe con la obra de Marc Richir: www.laphenomenologierichirienne.org 


\section{Consideraciones introductorias sobre el itinerario intelectual de Marc Richir}

Antes de entrar de lleno en cuestiones propiamente filosóficas, empecemos por aludir a algunos datos biográficos que no por parecer externos a la filosofía carecen de relevancia. Marc Richir nace en 1943, en Bélgica, cerca de Charleroi. Es francófono, belga de origen valón. Su contribución a la fenomenología en general y a la fenomenología en lengua francesa en particular es hoy, sin duda, indiscutible. Este último dato, conjugado con el anterior, relativo a su procedencia o, si se quiere, a la especificidad de su origen dentro del ámbito francófono, no es en absoluto baladí. No lo es porque en virtud de este origen no francés (aunque francófono) hay en su obra una cierta distancia crítica respecto del peso excesivo, en ocasiones acríticamente asumido, que la filosofía francesa ha tomado durante la segunda mitad del siglo XX, al punto de pretender ser casi exclusiva depositaria de parte de la tradición alemana de principios de siglo $\mathrm{y}$, sobre todo, pretender erigirse en su legítima heredera.

"Fenomenología" es, desde luego, uno de los nombres fundamentales de ese imborrable legado que nos deja la filosofía en lengua alemana de finales del XIX y principios del XX. Ahora bien, cierta recepción francesa de ese legado ha obliterado, como sabemos, la importancia de algunos de sus autores. Uno de ellos es, sin duda, el propio Husserl. Evidentemente, lo que aquí apuntamos no corresponde ya a la situación presente. Ahora bien, eso se debe a ciertas resistencias frente a lo que fue el modo en que se entendía la fenomenología en territorio francófono allá por los años 70 , y hasta bien entrados los 90. Richir fue una de esas voces discordantes. Unida a otras, de ámbitos varios, ha hecho que la obra de Husserl, y la paulatina publicación de su Nachlass, desprendan una extraordinaria vitalidad. Lo que hoy es una realidad no iba entonces de suyo. Ahora bien, ya desde principios de los años 70 podía percibirse en Richir una distancia crítica respecto de una recepción, la francesa, demasiado polarizada por un Heidegger que se incensaba en demasía. Distancia que, por ejemplo, brilla por su ausencia en otros fenomenólogos de la generación de Richir como Jean-Luc Marion, o incluso en pensadores algo anteriores como Henri Maldiney. ¿Qué decir de ese tipo de recepción de la fenomenología del que Richir se distancia? ¿Cabe resaltar en ella algún rasgo que la defina? Yo diría que lo propio de esta recepción heideggeriana y luego derridiana de la fenomenología reside en el motivo manido y recurrente de la superación, así como la consectaria identificación de la obra de Husserl con una suerte de "capítulo de la metafísica", e incluso con una consumación de la metafísica de la presencia. A contrapié de esto último, puede entenderse la recuperación richiriana de Husserl como el intento de ver que hay toda una serie de experiencias esenciales tratadas por Husserl 
que escapan a la rúbrica de la metafísica de la presencia (fundamentalmente las relativas a la Einfühlung y a la Phantasie) ${ }^{2}$.

Hechas estas precisiones y enunciada, por así decirlo en negativo, la posición de Richir ante el legado de la fenomenlogía, ¿qué decir de más sobre su recepción de Husserl?, ¿cuál es, a grandísimos rasgos, la relación de Richir con la obra del fundador de la fenomenología? Es esencial señalar que Richir no se considera tanto un crítico de Husserl cuanto un continuador. Un continuador que entiende retomar el espíritu de la fenomenología y, en nombre de ese espíritu, combatir, por veces, su letra. De este modo, el papel de Richir es, más bien, el de un refundador. Ahora bien, se trata, si se quiere, de un refundador "inmanente", es decir, y como veremos, de un "refundidor". ¿Qué se quiere decir con ello? Sencillamente que esa refundación usa de materiales ya presentes ordenándolos de modo distinto, u osando, por así decirlo, otras aleaciones. Su refundación es pues, como dice el propio Richir ${ }^{3}$, "refundición".

¿Pero refundición de qué? Refundición de la fenomenología entera (por cuanto trastocar los fundamentos atañe necesariamente al resto del edificio), mas, fundamentalmente, refundición de aquellas partes que no responden - entiende Richir - al espíritu de la fenomenología sino a designios sistemáticos en exceso - exceso de sobrepujamiento - sobre las cosas mismas. Es, en parte, el inevitable exceso de lo simbólico sobre lo fenomenológico. Pensemos, por ejemplo, en ciertas tesis metafísicas sobre el infinito (continuo) del tiempo, o la idea de un eidos ego a que habría de someterse a priori la intersubjetividad transcendental, o la exigencia de pensar la phantasia como una modificación de la percepción, y así pre-conceptuar el no presente fantaseado como quasi-presente (representificado). Exigencias que no siempre, en Husserl, nacen de las cosas mismas sino, antes bien, de una incoercible tentación de sistematicidad de la que ningún filósofo está a recaudo; ni siquiera Husserl, a pesar de su inmenso talento analítico y su denodada determinación a habérselas con "sulas cosas mismas".

Preguntemos ahora: ¿Refundición con qué y a partir de qué? Los materiales básicos de esta nueva aleación (que arrojará una estructura arqui-

${ }^{2}$ Por la misma razón, la relación con las fuentes en general, y con las fuentes alemanas en particular, resulta, en Richir, muy directa. Su recepción de Husserl está muy apegada a los textos; aunque no a aquellos que suelen comentarse. Otro tanto puede decirse de su lectura del idealismo alemán, esencial en Richir, esencial para su fenomenología. Recordemos que Richir ha traducido algunos textos de Schelling, de Fichte, y también de Husserl, y dirige una colección, la colección Krisis en la editorial Jerôme Millon, que ha acogido una gran cantidad de traducciones de Hussserl al francés. Su labor de revisión y edición de traducciones ha sido y sigue siendo muy activa.

${ }^{3}$ Cf. RICHIR, M., «La refonte de la phénoménologie", en Annales de Phénoménologie $\mathrm{n}^{\circ} 8$, Amiens, 2009. 
tectónica, ordenada y no rapsódica, pero nunca cerrada y de una pieza) son aquellos materiales que aparecen como intrínsecamente aporéticos en la obra de Husserl. Fundamentalmente, la intersubjetividad y la phantasia (aunque también el tiempo y la corporalidad, elementos, éstos, necesariamente conjugados con aquéllos). Vale como matriz de refundición aquello que introduzca un desfase, un desajuste (écart) en cualquier tipo de continuo (sea este temporal, espacial o eidético). Sobre este género de materiales refractarios a toda sutura sistemática (recordemos los ingentes esfuerzos "monadológicos" con los que Husserl busca cerrar eidéticamente la intersubjetividad transcendental) tratará Richir de asentar de un modo distinto el edificio entero de la fenomenología.

Lo hará de un modo no rapsódico (por arquitectónico) pero no sistemático en el sentido de cerrado, sino esencialmente abierto. Prueba de esto último la encontramos en el descubrimiento, al correr de los años, de algunas nuevas mediaciones arquitectónicas, entre determinados registros, el descubrimiento de estratos con entidad arquitectónica propia y que, en esbozos pasados, inevitablemente fueron pasados por alto. Así, por poner un ejemplo, el registro del "espacio del adentro" se elabora por sí mismo y con creciente claridad tan sólo a partir de 2010. De hecho, y por hablar con mayor precisión, hace su aparición en el apéndice del libro Variations sur le sublime et le $\mathrm{soi}^{4}$ y se desarrolla con creciente detalle en otras obras posteriores. "Espacio' del adentro" es el nombre que agrupa un determinado tipo de desajuste, un cierto tipo de fluctuación del nada sino fenómeno. Así, por caso, el "espacio" del adentro no es ya esquemático (el esquematismo es un género de desajuste un punto más fundamental), pero tampoco es aún el espacio topológicamente centrado y geométrico, es decir, el espacio del afuera. A ese espacio del afuera corresponde el "adentro" entendido desde un punto de vista meramente naturalista y anatómico. Sirva esto para clarificar que el "espacio" del adentro no es, en suma, el adentro de las vísceras, los huesos, los músculos. Ese adentro fisiológico es un espacio que ya es el espacio - sin comillas - del afuera.

Hay otro dato más hay que contribuye a comprender esa distancia crítica con la filosofía que se da en Richir. Distancia crítica que también es la propia de la fenomenología. Efectivamente, la fenomenología, decía Merleau-Ponty, tiene algo de filosofía fronteriza o filosofía a pique de dejar de ser filosofía, algo de una ocupación que vaca en la frontera entre filosofía y no filosofía, en un extraño equilibrio metaestable que pareciera indicar la extraña presencia de un territorio propio, algo así como un "campo fenomenológico", un dominio especifico de análisis. Cierto es que la fenomenología encar-

${ }^{4}$ Cf. RICHIR, M., Variations sur le sublime et le soi, J. Millon, Grenoble, 2010. 
na, respecto de la historia de la filosofía, un cierto paso a un lado (que nunca será un simple dar la espalda), y desde el cual la filosofía aparece, en parte, como tradición, como institución simbólica, como un determinado modo de organizar ese magma que es el vivir, con su proliferación de sentidos (el genuino material de la fenomenología). Así, esa sensibilidad fenomenológica por un afuera que ponga en solfa la institución simbólica de la filosofía le llega también a Richir, paradójicamente, de la seriedad de su incursión en una institución simbólica del todo distinta a la filosófica: la física. De hecho, a la filosofía sólo llega más adelante, tras haber estudiado Física, y haberla estudiado de modo bastante avanzado ${ }^{5}$.

Efectivamente, Richir terminará unos estudios de física especialmente duros en la universidad de Lieja. Escribirá una tesina sobre un problema de teoría de la relatividad, tras lo cual iniciará un doctorado. Un doctorado que supuso integrarse durante algo más de un año en un equipo de investigación que trabajaba en torno a cuestiones de biofísica. Más concretamente y para quien pudiera interesar, sus actividades de físico (como investigador de doctorado) se desarrollaron en el "departamento de física atómica y molecular" de la Universidad de Lieja, fundamentalmente durante el curso 1964-65. En esa misma universidad, como decíamos, culminó su licenciatura escribiendo una tesina sobre "El efecto Poynting-Robertson y su generalización a partículas no esféricas (en relatividad restringida y general)". En el doctorado que siguió a la licenciatura, y que no llevó a término, Richir proyectaba una tesis que estudiaba la radio-resistencia del benceno y sus polímeros en el marco de una investigación experimental sobre las moléculas de carbono de origen extra-terrestre. El proyecto investigaba el origen de la vida y manejaba la hipótesis de un origen exterior al planeta Tierra. En el marco de dicho proyecto, y dentro del trabajo de laboratorio necesario a la elaboración de su tesis, una de sus tareas fue ocuparse de la manipulación e interpretación de resultados de un aparato de resonancia paramagnética electrónico (EPR). Este sofisticado aparato, a cuyo cargo estaba Richir, servía para el estudio de los radicales libres generados por las radiaciones ionizantes sobre moléculas orgánicas. Por lo demás, algo después de ese trabajo de laboratorio, y mientras preparaba ya su tesis en filosofía, siguió en contacto con la ciencia. No sólo por el evidente interés que la ciencia siempre suscitó en él ${ }^{6}$, sino también por ejercer durante algunos años de profesor de matemáticas y de físicas en secundaria; más tarde, se ocupó de los cursos de Epistemología

${ }^{5}$ Previo al interés por la física, Richir tuvo y sigue teniendo un gran interés por la geología. Lo cierto es que en sus textos proliferan las metáforas geológicas.

${ }^{6}$ Cf. RICHIR, M. La crise du sens et la phénoménologie (J. Millon, 1990): partes importantes de la obra de Richir están dedicadas a la institución simbólica de la física, y tratan tanto la física newtoniana como la física cuántica. 
de la facultad de filosofía de la Universidad Libre de Bruselas, en ocasiones junto con el primero de sus doctorandos, Pierre Kerszberg. Por lo demás, participó durante años en el famoso seminario del importante filósofo Jean Ladrière, también sobre cuestiones de epistemología.

Sea como fuere, y como se habrá adivinado, la labor investigadora en física le genera cierto desencantado. Al desencanto se une una antigua afición por la filosofía (su lectura de Descartes, por ejemplo, es muy antigua) que, año tras año, va viéndose respaldada por diversas lecturas. Una de ellas, decisiva en ese contexto de investigación concreta en ciencias físicas, es la lectura de Kant y, más concretamente, de la introducción a la $2^{\mathrm{a}}$ edición de la Crítica de la razón pura. De esa lectura dirá en alguna ocasión, retrospectivamente, que le hizo comprender que la física no era lo que buscaba y que, a la luz de Kant, comprendió que había sido pitagórico sin saberlo.

Por otro lado, su interés en la idea de fenómeno alberga un origen no husserliano. Proviene de la temática kantiana de la ilusión transcendental. La cuestión de la suspensión también posee, en Richir, un origen no directamente fenomenológico, y corresponde a su lectura, antigua y continuamente renovada, de Descartes, filósofo esencial para Richir ${ }^{7}$. Recordemos que el núcleo esencial de la epojé fenomenológica hiperbólica richiriana reside en sostener, a modo de reproche, que Husserl no entendió enteramente la duda hiperbólica cartesiana, que no supo tomar toda la medida de la duda hiperbólica y la hipótesis del Genio Maligno. La radicalización de la reducción fenomenológica es claramente hiperbólica, de franca inspiración cartesiana. Radicalización que no es ruptura. En rigor, Richir sostiene que la matriz oculta que permite el movimiento de desapego o desasimiento (Enthaltung) propio de la reducción fenomenológica reside en una suerte de hipérbole oculta y con la que Husserl no terminó de ser consecuente. La matriz de radicalidad de la epojé fenomenológica radica en la epojé hiperbólica (de inspiración cartesiana); o, si se quiere, la teleología de radicalidad de la epojé fenomenológica lleva a la epojé hiperbólica, de la que resultan fenomenalizaciones inauditas (pues de eso se trata, de aquello a que una determinada epojé abre; no se hiperboliza por hiperbolizar sino por y para fenomenalizar concretudes cada vez más arcaicas).

Este incoercible interés por la filosofía, unido a su relativo desencanto por la física, desencanto y hartazgo de sus pautas de investigación concreta, le llevarán a estudiar filosofía en la Universidad Libre de Bruselas, donde,

${ }^{7}$ Cf. CARSLON, S., "El cartesianismo de Richir. Aproximación a la '3a Meditación Fenomenológica'” en Investigaciones Fenomenológicas nº, 2012. http://www.uned.es/ dpto fim/InvFen/InvFen09/pdf/19 CARLSON.pdf y "Reducción fenomenológica y 'reducción espinosista'. El hiper-cartesianismo de Marc Richir y el espinosismo de Michel Henry" en Eikasia n46, 2012 http://revistadefilosofia.com/46-05.pdf 
al haber cursado ya una carrera, integrará directamente el segundo ciclo. Muy rápidamente se interesará por la fenomenología, dedicando su tesina a Husserl y a la "Meditación Fundamental" de Ideas I. De esa tesina - que aún duerme en los estantes del archivo Husserl de Lovaina, donde Richir pasó algunas temporadas investigando - dirá Richir que le parece, a día de hoy, demasiado inspirada en Derrida. Efectivamente, Richir tuvo un temprano interés por el camino filosófico de Derrida, del que, andado el tiempo, se apartaría decisivamente para reencontrarse con la fenomenología de un modo distinto. El esquematismo de la fenomenalización en Richir tiene algo de la archiescritura derridiana y de la diseminación, pero con la importantísima salvedad de que el esquematismo (suerte de doble movimiento de la fenomenalización) hace, busca y toca con concretudes. El más acá del sentido sigue siendo sentido, incluso sentido exacerbado, en trance de eximirse de toda escala humana, sentido salvaje, "muda concreción" (por retomar una expresión de Husserl) y no disolución del sentido o diseminación significante.

A decir verdad, la obra de Richir también puede leerse como una serie de sucesivos "reencuentros" con la fenomenología de Husserl, reencuentros resultantes de revisar - por injustas - ciertas críticas dirigidas a la obra del fundador de la fenomenología. Revisiones que corren en paralelo con el descubrimiento de valiosos pecios desperdigados por la obra póstuma (pero no sólo) de Husserl. Es notable, por ejemplo, el descubrimiento, hacia el 2004, con la publicación de Phantasia, Imagination, Affectivité ${ }^{8}$, del concepto husserliano de phantasia "perceptiva" que Richir rescata del texto $\mathrm{n}^{\mathrm{o}} 18$ del tomo XXIII de Husserliana9.

$\mathrm{Si}$, para concluir este apartado, nos remitimos a una reciente entrevista en la que Richir hace un interesante repaso de su trayectoria, advertimos que su interés por la fenomenología tal y como, a día de hoy, lo interpreta, resulta de una suerte de curva convergente de amplio radio donde el Idealismo Alemán juega un papel fundamental. Richir comenta, en esa primera parte de la entrevista, cómo la lectura de Husserl le llevó a Derrida, pero cómo salió de Derrida a través de Heidegger y de Heidegger a través de Fichte y de una profunda relectura del idealismo alemán. Esto, en último término, le hará considerar a Heidegger como un pensador que sólo tangencialmente, por accidente, roza la historia de la fenomenología (por contraste con otros pensadores como Merleau-Ponty o Patocka, que Richir sí considera auténticamente fenomenólogos). Heidegger terminará siendo, a ojos de Richir, un gran metafísico, que no es poco (aunque acaso un escalón por debajo de

\footnotetext{
${ }^{8}$ RICHIR, M., Phantasia, Imagination, Affectivité J. Millon, Grenoble, 2004.

9 HUSSERL, E., Phantasie, Bildbewusstsein, Erinnerung. Zur Phänomenologie der anschaulichen Vergegenwärtigungen. Texte aus dem Nachlass (1898-1925), Hua XXIII, editado por Eduard Marbach, The Hague, Martinus Nijhoff, 1989.
} 
Schelling). En todo caso, la historia de la filosofía, la institución simbólica que es la filosofía es algo diferente; diferente de la fenomenología.

Esa curva convergente desembocará en otra lectura de Husserl. Una lectura apoyada en manuscritos; una lectura más justa y paciente que las lecturas apresuradas, excesivamente mediadas por Heidegger o Derrida que polarizaron (aunque nunca de modo decisivo) algunas de sus críticas de juventud. Richir se expresa de este modo en la citada entrevista:

"Resulta siempre extremadamente difícil, incluso imposible, situar lo que pudo, originariamente, motivar un itinerario filosófico. Terminada una licenciatura de física, retomé los estudios para cursar, esta vez, filosofía. Enseguida sentí una especial afinidad con la fenomenología. Aunque lo cierto es que los vientos de la época (allá por 1968) corrían, desde luego, por otros derroteros: el estructuralismo, Heidegger, Derrida. Retrospectivamente visto, mi itinerario ha consistido en un larguísimo rodeo para reencontrarme con esa afinidad de origen, siguiendo una suerte de curva convergente que me hizo salir de Derrida a través de Heidegger, y salir de Heidegger por el idealismo alemán, etc., para, por fin, volver a la fenomenología" 10 .

Como decíamos, esa amplia curva convergente está mediada por una asimilación, fenomenológicamente inspirada, del idealismo alemán. Eso le llevará a escribir una tesis monumental dedicada a Kant, Fichte y Schelling. Vestigios de esa tesis, nunca publicada en su totalidad, son sus dos libros $A u$ - delà du renversement copernicien. La question de la phénoménologie et de son fondement, (M. Nijhoff, 1976) que es la introducción a la tesis y Le Rien et son apparence: fondements pour la phénoménologie (Ousia, 1979) que corresponde a la parte dedicada a Fichte. Escarbemos un poco en esta relación entre fenomenología e idealismo transcendental o en la entronización de este último como acceso privilegiado a esa refundición de la fenomenología que Richir entiende haber llevado a cabo.

10 "Il est toujours extrêmement difficile, voire impossible, de situer ce qui a pu motiver à l'origine un parcours philosophique. Après avoir terminé une maîtrise en physique, j'ai repris des études de philosophie. Tout de suite je me suis senti, avec la phénoménologie, "un air de famille". L'atmosphère de l'époque (en 1968) était cependant à autre chose : le structuralisme, Heidegger, Derrida. Mon parcours a été rétrospectivement un long détour pour retrouver ma famille d'origine, comme une courbe rentrante qui m'a fait sortir de Derrida par Heidegger, de Heidegger par l'idéalisme allemand, etc., pour finalement revenir à la phénoménologie". $C f$. RICHIR, M. "Autant de chantiers ouverts pour l'analyse phénoménologique", entrevista publicada en Le magazine littéraire $\mathrm{n}^{\circ} 403$, Paris, 2001, p. 61. Debemos esta cita valiosísima a la excelente tesis sobre Marc Richir, de próxima publicación, elaborada de CARLSON, S., De la composition phénoménologique. Essai sur le sens de la phénoménologie transcendantale chez Marc Richir, Tesis doctoral co-dirigida por Michel Dupuis y Guy Vankerkhoven, Université Catholique de Louvain-La-Neuve, 2014. 


\section{La pregunta por el "nada sino fenómeno (rien que phénomène)"}

Richir alberga la temprana convicción de que algo esencial de la fenomenología se juega ya en el devenir del idealismo alemán, aunque codificado en otros términos. ¿Qué decir de ello? No podemos por menos de recordar, en esa misma entrevista que ya hemos citado, estas otras palabras:

"Con todo, e incluso al margen de los itinerarios de Husserl y de Heidegger, lo que motivó mi meditación propia fue la pregunta por el estatuto del fenómeno como nada sino fenómeno (y no como fenómeno de otra cosa), fenómeno en realidad omnipresente en la tradición bajo la forma de lo que Kant llamó 'ilusión transcendental'”11

Efectivamente, se tratará de pensar lo que Richir llamará el "nada sino fenómeno (rien que phénomène)" como algo ciertamente otro, algo que yo no he formado, pero que - de ahí que la fenomenología sea la perspectiva basal - no puede pensarse sin mí (pues es, ciertamente, fenómeno, y no cosa en sí). Los desarrollos, llevados al límite en algunas partes de las obras de Fichte, Hegel o Schelling, nos permiten pensar esa alteridad dentro de la referencia obligada a la subjetividad (tal y como impone la opción teórica en que consiste la fenomenología). Se trata de pensar la alteridad, el carácter salvaje del fenómeno, sin recurrir de entrada a un realismo metafísico (como en Descartes o en cierto empirismo, como en gran parte de la filosofía anglosajona a día de hoy, o en el llamado "realismo especulativo" de cierta filosofía continental contemporánea ${ }^{12}$ ) o, sin acudir, en último término (caso de Kant), a un supuesto noúmeno, a una realidad en sí.

Se trata, antes bien, de pensar la paradoja de un "en sí" fenomenalizado o en clave fenomenológica y que comprometa al sujeto. He ahí la abismal paradoja que encierra la expresión "reflexividad del fenómeno" no bien nos atrevemos a situar la tara del genitivo del lado objetivo. Pensar pues un "en sí" fenomenológico, un barbarismo del sentido o de los sentidos proliferantes, pensarlos como "im-pre-pensables" (como unvordenklich según la expresión de Schelling), y hacerlo con rigor fenomenológico, es decir, sin presupuestos; sin presupuestos en el sentido que la puesta entre paréntesis de la transcendencia recibe en fenomenología: pensar pues lo "imprepensable"

11 “A l'écart cependant du cheminement de Husserl et de Heidegger, ce qui a motivé mes propres méditations était la question du statut du phénomène comme rien que phénomène (et non comme phénomène d'autre chose), phénomène présent partout dans la tradition sous la forme de ce que Kant a nommé "illusion transcendantale". $C f$. RICHIR, M., "Autant de chantiers ouverts pour l'analyse phénoménologique”, Entrevista publicada en Le magazine littéraire $\mathrm{n}^{\circ} 403$, Paris, 2001, p. 61.

12 Por ejemplo Quentin Meillassoux o Markus Gabriel. 
en estricta referencia a mi experiencia, en inmanencia con ella. ¿Qué puede ser eso? ¿Cómo acometer dicha tarea sin desactivarla en su efectividad por el simple hecho de acometerla y desde el mínimo de densidad performativa que esa acometida misma acarrea? ¿Cuál es la experiencia del rebasamiento de $m i$ experiencia en y desde $m i$ experiencia, cuál la experiencia concreta de eso que precisamente se llama "nada sino fenómeno" como concreta alteridad? Puede que un inicio de respuesta se cele en que acaso ese "mi" (de "mi" experiencia) esté multiestratificado, sea plurívoco (que no caótico), es decir, una vez más, arquitectónico (que no cerrado ni tampoco rapsódico), nunca de una pieza: hay una fundamental espectralidad de la facticidad transcendental.

Sentadas las bases del problema, que tiene todo el aspecto de una paradoja inatacable, Richir pensará, en el interior de la experiencia, diversos registros de fenomenalización (que serán otros tantos ritmos de temporalización/espacialización). En rigor, la disolución de esta aporía aparentemente monolítica no es sino el despliegue de la arquitectónica en sentido fuerte, en sentido fenomenológico. La aporía no se resuelve, sino que su aspecto monolítico se ve disuelto y reorganizado en diversas aporéticas estratificadas, en registros de problemas, de desajustes entre concretudes. He ahí el inaudito modo en que la fenomenología arquitectónica "avanza". Avanza gracias al despliegue - mediante análisis (mediante "reducción arquitectónica" dirá Richir) - de la autonomía relativa de los diversos registros de experiencia (de fenomenalización).

Un registro de experiencia se meta-estabiliza entre dos polos de fenomenalización arquitectónicamente establecidos. Eso mismo es la arquitectónica: sentar ciertos polos entre los que "parpadea (clignote)" el fenómeno pero que el fenómeno nunca alcanza, polos de exceso en los que el fenómeno jamás se abisma. Sólo así podemos organizar el campo fenomenológico y, mal que bien, orientarnos en él.

Sancionar el correlacionismo (fenomenológico o de otro género) como irremediablemente aporético, como esencialmente no apto para pensar un ipse "del" sentido (como sentido salvaje, parcialmente inhumano) que no mime ni refleje el ipse del sujeto ${ }^{13}$ es, de entrada, desconocer la realidad arquitectónica de la experiencia, del vivir mismo. Reparemos, una vez más, en que "arquitectónica" no se refiere, en Richir, a algo que se acometa después de la recogida de determinados resultados, algo así como una ordenación posterior de ciertas verdades locales (ni siquiera es ese el caso en Kant). Es, antes bien, una característica de la experiencia misma, pero en un sentido aún más fuerte que el de la influencia regulativa en la experiencia. Nuestra

${ }^{13}$ He ahí la estructura de lo que Richir llama "simulacro ontológico, y que, en últimas, sólo una epojé hiperbólica alcanza a suspender o desconectar. 
experiencia está constitutivamente multiestratificada. Más concretamente, es esta característica aquello que permite soslayar el riesgo de tautología que acecha tras todo correlacionismo (fenomenológico o no) sin por ello romper la verdad (fenomenológica) de dicho correlacionismo (sino, sencillamente, desplegarlo aquitectónicamente y pensar esa correlación a diversos niveles). En la ampliación arquitectónica de la fenomenología que propone Richir no hay tanto una ruptura de la correlación transcendental (contra lo que suelen sostener otros fenomenólogos contemporáneos) cuanto una complejificación, profundización y estratificación de la misma. Pensar la alteridad fenomenológica, el aporético "en sí" del fenómeno, su salvajería o barbarismo, requiere el despliegue de una multiestratificación (arquitectónica) de la correlación transcendental, pero eso no conculca el a priori de correlación; antes bien: lo confirma.

Lo confirma al precio de desposeernos, en parte, del mismo. Nos despoja y desposee de la posibilidad de asistir a su verdad (lo cual sí equivaldría a una versión intelectualista del correlacionismo) en determinadas latitudes las más arcaicas - de la experiencia. Latitudes donde si bien no asistimos a la correlación entre lo profundo de mi vida y las concretudes fenomenológicas que en esas profundidades son "tocadas" (por "tact interne" gusta Richir de decir, citando en esto a Maine de Biran ${ }^{14}$ ), sí que, querámoslo o no, asistimos - en sentido transitivo - la parte "mundo" o "alteridad transcendente" del a priori de correlación, es decir, las concretudes fenomenológicas que entran en concrescencia con las zonas arcaicas de nuestra afectividad, parajes íntimos y extraños a la vez, y a los que sólo tenemos un acceso indirecto. Nuestra "nescencia" (límite del asistir a) garantiza la verdad y la efectividad de la correlación, la amplitud del asistir, del alumbrar - que decimos también - un sentido, pero, en los registros más fundamentales, bajo la forma de concretudes prelingüísticas en absoluto ajenas al sentido. Más bien todo lo contrario: acreciones afectivas con sentido que disparan y relanzan la labor esquemática. Ese despliegue es, precisamente, el fenómeno de lenguaje.

En suma, lo que, fenómeno, irrumpe en mi vida, marca su alteridad al imponer un tiempo, un ritmo y un espacio propios. A esos ritmos suyos también responden partes arcaicas de mí, partes mías, pero partes tan sumamente profundas que me resultan indisponibles, no directamente accesibles. De puro serlas, atravesarlas, empuñarlas, me resultan prácticamente invisibles.

${ }^{14} C f$. UMBELINO, L., "Affectivité, mélancolie et aliénation. Marc Richir lecteur de Maine de Biran" en Annales de Phénoménologie, nº13, 2014. Amiens. pp. 145-157. Se pueden consultar también los siguientes trabajos del mismo autor, muy pertinentes para los temas que estamos tratando: "Da Stimmung. Biranismo e Fenomenologia" in Arbor, ed. Consejo Superior de Investigaciones Científicas, Madrid, vol. CLXXXV, $n^{\circ} 376$ (2009), pp. 437-448. 
Efectivamente, esas partes profundas de mí (que, repito, no rompen, sino que confirman - sólo que a otros niveles - la correlación transcendental) no me son directamente disponibles, movilizables, o invocables desde el registro de experiencia en el que acostumbro a moverme, a reconocerme, según las coordenadas de lo que Richir llama "institución simbólica", y donde las cosas, los seres, las acciones y acontecimientos están unívocamente recortados ${ }^{15}$. Dicho de otro modo: no hay una ruptura de la correlación, sino un desfondamiento arquitectónico de lo que yo creía ser el único nivel de correlación (falsa unicidad que comunica con esa otra falsa unicidad de que se alimenta el naturalismo cientificista). No es la correlación lo que esta refundición de la fenomenología rompe, sino su univocidad. La correlación se dice, se declina, según diversos registros de fenomenalización. Una vez más: hay espectralización de la facticidad transcendental. A ese análisis espectral denomina Richir "reducción arquitectónica".

Es pues esencial comprender que la transcendencia se desplaza no sólo del lado del mundo, hacia horizontes insospechados. También se desplaza en "mi" interior, y lo hace a profundidades afectivas que consuenan, del lado del mundo, con lejanías inauditas, hojaldrando, por así decirlo, los sentidos de ese "mi".

En una ocasión le oí a Richir una formulación bastante clara de lo que entendía haber intentado en fenomenología o, para ser más precisos, en su fenomenología del lenguaje (que es un modo de declinar de modo específico pero también estratégico el problema general que hemos dibujado). Se trataría, para Richir - y, repito, en palabras de éste (palabras habladas; no escritas; al menos hasta donde yo sé) - no tanto, como había hecho Lévinas, de apuntar y subrayar la esencial diacronía de ciertos sentidos (esa antecedencia de la llamada del otro), sino de hacer una concreta fenomenología de esa experiencia de diacronía, tratar pues de analizar detenidamente esa descoordinación (una de cuyas matrices es eminentemente temporal) entre el ritmo de mi presente y lo que en él aparece o transparece ${ }^{16}$. Analizar, en

${ }^{15}$ Se trata, por ejemplo, de la ontología requerida para que los códigos jurídicos sean posibles: interpretables y aplicables. La ontología de las promesas que toman la forma de contratos. Hay, ciertamente, promesas de temporalización del sentido - lo que Richir, con Schelling, denomina "futuro transcendental" o "futuro proto-ontológico" - que encontramos en otros registros arquitectónicos, más arcaicos, las más veces inadvertidos, pero virtualmente necesarios para la concreción de la vida, y ello así suela ésta entenderse, erradamente, como desplegándose en el único plano del presente continuo, con su pasado - un pasado que fue presente - y su futuro - un futuro que tomará, algún día, la forma de un presente.

${ }^{16}$ A este respecto es especialmente ilustrativo un texto en el que Richir nos habla de su recorrido fenomenológico y que encontramos al principio de su obra Phénoménologie 
cierto modo, el a posteriori de la diacronía, o el modo en que, en el a posteriori (pues es fenomenología - y no metafísica - lo que hacemos), se marca y se dibuja su a priori. La experiencia del hacerse del sentido constituye un lugar privilegiado de desarrollo de este programa. Ello, sencillamente, porque es un revelador privilegiado de la multiestratificación del propio vivir como vivir que, humano, y por ello intrínsecamente desajustado respecto de sí mismo, ha de habérselas, quiéralo o no, con el sentido: no somos animales, ni dioses, ni tampoco máquinas.

\section{Inconsciente simbólico e inconsciente fenomenológico}

Si la fenomenología no es mero fisicalismo, si no se deja reducir a naturalismo, es porque trabaja en y con el elemento del sentido. Los fenómenos no son meras señales brutas. Creerlo en nombre de un empirismo supuestamente radical constituye una posición metafísica. De hecho, todo el empeño que preside a los múltiples análisis sobre la síntesis pasiva acometidos por Husserl descansa en mostrar cómo las sensaciones están ya transidas de sentido, y ello a un nivel elementarísimo antes del cual es absurdo remontarse. Absurdo porque la remontada, en todo caso, arrojaría un esquematismo de sentido aún más denso, aún más violento e inhumano pero no por ello carente de sentido. Todo lo contrario. Antes bien, el regressus fenomenológico arroja una urdimbre - hecha de proto-protenciones y proto-retenciones - demasiado vertiginosa, hojaldrada según distintos ritmos, demasiados "a un tiempo", demasiados "a la vez" como para que nosotros, humanos, podamos siquiera irles en los alcances. No hay grado 0 del sentido. O, si se quiere, sólo lo hay en una filosofía contaminada de cientificismo. Por eso - decíamos - la posición de cierto empirismo histórico es, como se sabe, metafísica y, en último término, no empirista o siquiera positivista. De ahí la boutade de Husserl, no exenta de profundidad, al proclamar eso de que "nosotros", los fenomenólogos, somos los verdaderos positivistas. Los positivistas de las "cosas mismas"; con la importante salvedad de que esas "cosas mismas" no son las que la ciencia aísla, mide, estudia y manipula a escala directamente quirúrgica (la escala del cuerpo propio, de las manos) o por la intermediación de instrumentos (escala transcendentalmente deudora de la escala directamente quirúrgica o "quirial").

Una vez más, pero reformulado esto último de un modo ligeramente distinto: la remontada más acá del sentido nunca implica la eliminación del sen-

en Esquisses, del año 2000, obra estratégica al ser la entrada en escena de la problemática de la phantasia como elemento esencial de refundición de la fenomenología. $C f$. RICHR, M., Phénoménologie en esquisses. J. Millon, Grenoble, pp. 25-27. 
tido sino, en el mejor de los casos, el hallazgo de configuraciones de sentido más arcaicas. Digo bien hallazgo porque el "dibujo" de su concrescencia, la acreción en que consisten, no la he hecho yo. Me topo con ella. Y ese toparme se manifiesta de un modo fenomenológico (y no ingenuamente realista) bajo la forma de afecciones que me sobrecogen y de inercias esquemáticas que me desposeen y, al tiempo, me refrescan pues despiertan algo muy profundo de mí que se pone a consonar con lejanías de mundo, con inminencias de toda la vida, siempre a pique de fenomenalizarse pero apenas "entre-apercibidas" en parpadeo (como dice Richir) sencillamente porque no son los tiempos y los espacios que nuestra subjetividad es capaz de fenomenalizar y, sobre todo, de estabilizar. Tan sólo irrumpen en parpadeo, y precisamente en virtud del hecho de que nuestra Leiblichkeit - como órgano de la fenomenalización - con ser finita, no consta de un límite reificado, fijado, establecido: es indefinidamente finita $\mathrm{o}$, si se quiere, indefinidamente infinita. Precisamente por ello las sensaciones, incluso en su comparecencia más arcaica, nos dicen algo o significan (en un sentido amplísimo) algo para nosotros. Ocurre, simplemente, que esa participación en y del ámbito del sentido no implica que esas configuraciones de sentido afectivo nos sean directamente accesibles. Son sentidos (afectivamente) sentidos. El acceso, salvaje, es, primero, afectivo. Sólo después admite un despliegue de apropiación: el esquematismo y lo que será un fenómeno de lenguaje. Ahora bien, no quiere esto decir que el sentido nazca con el fenómeno de lenguaje consciente o en posesión de sí. Antes bien, el sentido se siente, afectivamente, y luego se retoma, de un modo explícitamente esquemático. Ese modo relativamente explícito y atento conforma la "fase de presencia" de un fenómeno de lenguaje. De idéntico modo, el momento en que el sujeto intenta apropiarse de un sentido (que le concierne) tampoco es el inicio del "esquematismo". Por eso nos dice Richir que el esquematismo de lenguaje es re-esquematización de un esquematismo fuera de lenguaje ${ }^{17}$ donde el sentido está por así decirlo entremezclado con la afectividad o donde la afectividad es directamente significativa.

La diferencia con el carácter eminentemente hermenéutico de la Stimmung en Heidegger está en que estas afecciones arcaicas de que habla Richir revelan cosas de mundo y de nosotros mismos originariamente plurales y que nada tienen que ver con nuestro proyecto (proyecto simbólico, en suma) y su sentido en relación a la vida como una totalidad (cerrada por la muerte). Son mundos plurales aún por fenomenalizarse, mundos en eterna inminencia, que, inadvertidamente contribuyen a la concreción de lo que superficialmente entendemos por "mundo". Contribuyen a ella desde su inacabamiento. Las afecciones arcaicas son una rauda incursión en esos mundos, una súbita

${ }^{17}$ Cf. CARLSON, Sacha, "Aproximaciones richirianas a la fenomenología del lenguaje", publicado en Eikasia, no47 http://revistadefilosofia.com/47-18.pdf 
descubierta, una rasada repentina. Las Stimmungen arcaicas nada revelan del Ser o de mi ser, nada sobre cómo me va o cómo le va al proyecto de mi vida; antes bien revelan algo que tiene profundamente que ver con nosotros y con arcanos de mundo de toda la vida (las inminencias de siempre, que siempre lo vienen nimbando, que siempre lo nimbarán), pero con las que nada podemos hacer, que no pueden servir directamente (sino, todo lo más, transposición arquitectónica mediante) para componer un proyecto de sentido al que convenga cualquier pregunta por el ser (del Dasein, o de cualquier otro ente). La muerte, y con ella el proyecto existencial que supuestamente somos, rubricado de acuerdo a la finitud que impone la muerte, se hallan, aquí - i.e. en estos órdenes de fenomenalización - enteramente fuera de juego. Lo que de nuestra afectividad se ve conmovido por los esquematismos fuera de lenguaje (e incluso por el esquematismo de lenguaje como re-esquematización de los esquematismos fuera de lenguaje, y que Richir llama los "fenómenos de mundo" como referentes de los "fenómenos de lenguaje") no es territorio que se sienta acuciado por la muerte. No hay, por parte de Richir, un rechazo de la finitud, sino, teniendo en cuenta esos otros estratos de fenomenalización, otra forma de comprenderla. Acaso sea nuestro acceso a ello lo de veras finito. Ahora bien, todo ello, todos esos parajes de la afectividad que responden a arcanos de mundo de toda la vida, tienen más de una inocencia y jovialidad nietzscheanas, la propia de la inocencia del devenir, que del ser-para-la-muerte heideggeriano.

Esta afectividad arcana pertenece a un "inconsciente fenomenológico" que tampoco debe confundirse con el "inconsciente psicoanalítico", ni tampoco con el inconsciente jungiano, que estudia los arcanos de la Institución Simbólica (de modo parejo a como ya lo hacía La filosofía de la mitología de Schelling). Ambos inconscientes, el simbólico y el fenomenológico, representan, en rigor, dos géneros dispares de inaccesibilidad. El "inconsciente simbólico" cierra el fenómeno de lenguaje o induce lagunas en fenomenalidad, es de carácter privado y tiene que ver con el enigma simbólico que cada quien es para sí mismo. En ese misterio se espejean los misterios, más profundos, de las instituciones simbólicas en general. Por el contrario, el "inconsciente fenomenológico" abre el fenómeno de lenguaje sobre una indefinición, sobre una profusión y riqueza que rebasa la capacidad de esquematización del sujeto y al tiempo lo salva de la idiocia, lo pone, sin menoscabo de su singularidad, en tesitura de interfacticidad transcendental. El inconsciente simbólico cubre ángulos muertos del fenómeno de lenguaje; el inconsciente fenomenológico es lo que el fenómeno de lenguaje no alcanza a esquematizar o tan sólo esquematiza en parpadeo. El inconsciente fenomenológico rebasa, ciertamente, al sujeto, aunque no - repitámoslo - de modo absoluto y definitivo: los límites de la transpasibilidad no pueden (en todo sujeto sano) ser fijados a priori pues lo que define a la transpasibilidad es, 
precisamente, eso: carecer de a priori y poder conculcar inopinadamente todo presunto límite de la experiencia. Por ello, las vislumbres sobre el "inconsciente fenomenológico" se dan en parpadeo; se entre-aperciben las afecciones arcaicas, y los paisajes de mundo que consuenan con esas acreciones de sentido sentidas.

El horizonte del inconsciente fenomenológico emerge al albur de determinadas experiencias. Por antonomasia al albur de una de ellas, que no es otra que la experiencia de tratar de decir algo, es decir, de la experiencia que da lugar a lo que Richir denomina "fenómeno de lenguaje". Tratemos de examinar más de cerca la anatomía fenomenológica del fenómeno de lenguaje.

\section{4. ¿Qué es un "fenómeno de lenguaje"?}

El íncipit del fenómeno de lenguaje reside en "algo" que se nos impone, y que, sin ser ajeno al territorio del sentido, es relativamente extraño a los sentidos verbales o lingüísticos de que disponemos. Precisamente por ello, porque hace sentido para nosotros aun sin saber muy bien todavía cómo o cuál, precisamente por ello - aducíamos - tratamos de decirlo. Para saber qué es lo que sé, por y para eso hablamos, como ya decía Merleau-Ponty, cuya influencia en la fenomenología del lenguaje de Marc Richir es indudable a pesar de las notables distancias que, al correr de los años, ha ido tomando Richir (hasta el punto de basar su arquitectónica en la phantasia, desplazando a la percepción del privilegio que le otorgaba Merleau-Ponty). He ahí, decíamos, el íncipit del fenómeno de lenguaje: sabemos que hemos dado con algo, que hemos topado y tocado con algo, con un sentido por lo pronto afectivamente notado, sentido, una acreción de afectividad sobre la que se volverá el esquematismo. Sabemos y no sabemos, al tiempo, lo que tenemos que decir. Al menos sí lo sabemos lo suficientemente bien como para juzgar las expresiones que se arriesgan a decirlo y descalificar una expresión, un determinado ensayo de captar tal o cual sentido, y estatuir con sorprendente seguridad, que, por ejemplo, equivoca su blanco, que no es eso en absoluto o que no es eso aún aunque se acerca.

El fenómeno de lenguaje nace, en definitiva, de una dimensión de anonimato propia del sentido y respecto de la cual ya siempre estamos retrasados. Es como si lo que tiene para nosotros sentido ya siempre lo hubiera tenido siquiera un punto antes de parecérnoslo, de sernos significativo, de decirnos algo. Es como si esa antecedencia fuera la garantía de la recepción del sentido; o, acaso, de su recepción fecunda y no traumática. Ahora bien, eso que llamamos "antecedencia" del sentido, también es antecedencia del propio pensar, como si éste se adelantase a pensar algo y al punto volviese sobre ello, tratando de recordar lo comprendido. A este doble movimiento de 
avance y retroceso simultáneos (simultaneidad que nada tienen que ver con la simultaneidad de un ahora) apunta Richir con el término de esquematismo. El fenómeno de lenguaje es un tipo determinado de esquematismo. En rigor, el fenómeno de lenguaje no es otra cosa que esa experiencia de toma de posesión progresiva de un sentido (ya sentido como sentido) por el que esos avances y retrocesos del pensar respecto de sí mismo y respecto del fenómeno se van civilizando, estabilizando, entrando, lento a lento, en posesión de sí.

Esta experiencia es, en suma, asimilable, mutatis mutandis, a lo que Husserl llamaba la Sinnbildung, a pesar de los enormes problemas que el modelo de una temporalidad continua como basamento fundamental de la vida de la conciencia induce a la hora de pensar, precisamente, la vida del sentido, la conciencia del sentido haciéndose. La Sinnbildung, llegada a un determinado nivel de maduración (a esa civilización de las ante-cipaciones y retro-cipaciones del pensar), desembocará en una Sinnstiftung cuya ejecución es hasta cierto punto localizable en el registro arquitectónico del continuo de los presentes. La Sinnstiftung (de los Sinngebilde) tiene, ciertamente, la virtud de fijar el sentido, de permitir re-ejecuciones del mismo, de asegurar su intersubjetividad (pues su interfacticidad ya es efectiva en el proceso mismo del sentido haciéndose, que es directamente interfacticial) pero comporta el defecto de borrar, en parte, el proceso venturoso de la Sinnbildung y, en suma, el íntimo sentido de la propia Sinnstiftung.

Para captar toda la envergadura de la problemática richiriana del sentido haciéndose o sentidos in fieri, hemos de tener presente que la expresión "fenómeno de lenguaje" ha de entenderse en un sentido amplísimo. Dicho de otro modo: no tiene por qué darse la explícita intención de decir algo, aunque esto último siempre acabe aconteciendo. Acontece, cuando menos, siempre que se pretenda fijar el sentido haciéndose en una expresión. Ahora bien, independientemente del posible destino de expresión de un sentido haciéndose (expresión en un poema, en una novela, en un tratado filosófico, en una obra de teatro, en un cuadro, en una pieza musical, o incluso en una performance) una "tensión de comprensión" puede ser perfectamente inconsciente. Es, incluso, una necesidad corporal, un estar a bien con uno mismo ${ }^{18}$. Por eso, este hacerse del sentido, en su ya mentada esencial precedencia, se vive y se siente como una tensión, como algo pendiente de resolución y somatizado en su carácter irresuelto. Somatización que las más de las veces se nota precisamente cuando el sentido en vilo (que sería una forma de traducir ese "en porte à faux" que muchas veces emplea Richir) halla su resolución. La tensión en la que nos encontrábamos aparece ahora merced al contraste con el alivio que la resolución produce. Vivíamos en una tensión de irresolución

${ }^{18}$ No en vano, Richir habla en este contexto de Sehnsucht recuperando un término básico del romanticismo alemán. Sehnsucht que busca colmar el desajuste esquemático. 
respecto de un sentido y no la notábamos de puro vivir en ella. Ahora aparece por contraste con el alivio que la resolución trae consigo. Alivio somáticamente sentido.

Una Sinnbildung inconsciente, una temporalización inconsciente del sentido puede ser la que resulta de darme cuenta de un enamoramiento. O acaso de su contrario, de darme cuenta (de que termina por temporalizarse) que no lo estoy. Dichas temporalizaciones pueden ser extraordinariamente lentas. Las Sinnbildungen pueden darse también a mayor escala: individualmente sentidas (a lo cual obliga el marco teórico de la fenomenología) su escala puede ser genuinamente supraindividual. He ahí la base de una fenomenología de la historia o de una fenomenología de lo político ${ }^{19}$. También, ciertamente, en la Sinnbildung que se juega en la intención explícita de decir algo (por ejemplo, expresar una sensación muy particular) hay partes inconscientes involucradas, incluso todo un cortejo amplísimo, tectónico, de formaciones de sentido que, nimbando el sentido principal que trata de decirse, se modifican también, pero lo hacen según un género de temporalizaciones más arcaico e inasequible.

En cualquier caso, "fenómeno de lenguaje" tiene, en Richir, una acepción muy amplia, sencillamente porque no sólo el sentido sino el esfuerzo por desentrañarlo ya siempre está encauzado. Así y todo, en "fenómeno de lenguaje" late la idea de una reasunción esquemática (reprise schématique), algo así como darle un relevo a un movimiento ya encauzado o, cuando menos, incoado: sentir que un sentido se está haciendo y darle pábulo, asistirlo, proseguir y contribuir a su maduración.

Cumple, sobre todo, distinguir claramente el "fenómeno de lenguaje" de otro tipo de experiencias de comprensión de sentido. Así, no todo lo que tiene que ver con el sentido es "fenómeno de lenguaje". No hay "fenómeno de lenguaje" donde no se da sino una simple comprensión de un sentido convencional, de algo ya establecido pero relativo al sentido. Es, por caso, el trato típico con las señales. Así, por ejemplo, hay trato con el sentido pero no hay fenómeno de lenguaje en el ejercicio de comprender determinado tipo de señales de tráfico u otras convenciones que nos permiten orientarnos en sociedad. Esas señales no se comprenden mediante un "fenómeno de lenguaje"; configuran, antes bien, nuestra animalidad simbólica. Pero no quiere esto decir que no haya convenciones (como puedan ser, por ejemplo, los signos lingüísticos) que, en un momento dado, usemos para expresar sentidos en pos de los cuales se aventura un fenómeno de lenguaje. De ese modo, hay

19 Richir ha explorado estos campos en varias de sus obras. $C f$. RICHIR, M. Du sublime en politique, Payot, Paris, 1991 o la obra más reciente La contigence du despote, Payot, Paris, 2014. (Existe una traducción al castellano: La contingencia del déspota, Brumaria, Madrid, 2013). 
convenciones, propias de la institución simbólica, que integran fenómenos de lenguaje: una metáfora poética, por ejemplo, está compuesta por signos lingüísticos, establecidos por convención. Estos signos, junto con sus significados o referencias primeras y directas, han de ser suspendidos para que, tras ellos, funcione el fenómeno de lenguaje. En todo caso, son fenómenos de lenguaje todas las elaboraciones simbólicas; aunque más preciso sería decir que "hay" fenómeno de lenguaje en todas las elaboraciones simbólicas. Las piezas básicas de una metáfora, sus significantes y significados directos, tienen y han de tener un sentido fijado. Sin embargo, la metáfora como tal está abierta al vilo (al porte-à-faux) de una Sinnbildung.

También es importante hacer notar que hay fenómenos de lenguaje, fenómenos de formación de sentido, relativamente independientes del uso del lenguaje sensu stricto, es decir, del lenguaje de palabras. Como hemos sugerido, la acepción de "lenguaje" es muy amplia en Richir, y se opone al término "lengua", que sí se refiere al sistema establecido de una lengua determinada. Así, por ejemplo, puede ser ya fenómeno de lenguaje una mirada que capto. Incluso fenómeno de lenguaje expresamente constituido en intersubjetividad. Sé que tal mirada hace sentido (ocurre con toda mirada que no sea abiertamente inquietante o directamente traumática), un sentido que, en lo más profundo de mi afectividad, he comprendido. Ahora bien, ese sentido necesita un desarrollo, una temporalización: la de su expresión (que sí puede ser lingüística) y su consectaria estabilización (Sinnstiftung). Lo finalmente expresado ya siempre tuvo su núcleo prelingüístico de sentido (bajo la forma de una iluminación, de una idea súbita). El trance entero que va de la iluminación (que puede ser de naturaleza poética, pero también filosófica, jurídica, política o matemática) a su expresión (en un poema, tratado, código, ley o fórmula) es el fenómeno de lenguaje.

Ante cierta concepción posmoderna de lo originario, que conduce a una diseminación absoluta, es importante reseñar que, en Richir, el momento anterior a la Sinnstiftung no es en absoluto un estado de absoluta delicuescencia, sino de indeterminación concreta, pendiente de ser expresada. Lo originario es, en Richir, una pluralidad más fuertemente cohesionada si cabe, pero de una cohesión cuyos ritmos no están a nuestra escala. Que ese género de cohesiones sin concepto se produce a una escala distinta a la de mi temporalización se manifesta por ejemplo en la experiencia siguiente: una metáfora en un poema puede sugerirme algo muy preciso y profundo que se pone en marcha al leerla. Andado el tiempo, puedo volver al poema y notar cómo la temporalización de sentido que desencadenaba dicha metáfora vuelve a ponerse en marcha, y lo hace con la frescura de antaño. Vuelvo a notar ese mismo vilo, esa misma indeterminación que, relativamente impermeables a mi tiempo biográfico o incluso al tiempo de la historia y de las sociedades, proceden de 
ciertos arcaísmos de la fenomenalización con sus ritmos de temporalización y espacialización. Esa mismidad que noto en la filigrana del sentido in fieri y de sus concretos horizontes de indeterminación, evidentemente, no tiene que ver con la mismidad de las palabras y menos aún con la mismidad de la sucesión de significantes que rubrican, muy superficialmente, la metáfora en cuestión. La "identidad" de esta ristra de significantes permite cierta localizablidad y repetabilidad, cierta transmisibilidad no esencial al fenómeno pero que responde a ciertas condiciones materiales coadyuvantes del hecho de la transmisión y de la tradición (oral o escrita). Sin embargo, no descansa en esa mismidad o identidad significante el ipse del sentido. Toda la dificultad está en pensar un ipse más acá de lo conceptual.

Lo esencial de la metáfora lograda, de la imagen poética que prende, que nos sobrecoge, que nos deja con las ganas de escudriñarla más a fondo pues nos parece que toca algo fundamental, esa indeterminación que en el extremo de esas palabras vive y late no es -y esto es fundamental - cualquiera, no es pura indeterminación sin cualificar. Lo que tengo, antes bien, es la captación fenomenológica de una singularidad. A eso mismo se refiere Richir con el ipse del sentido, su Sachlichkeit.

Bien pensado, su indeterminación no es más que un efecto arquitectónico: lo que a mí, desde determinado registro arquitectónico, me parece, el modo en el que eso se me da. Así pues las Sachlichkeiten no son de suyo indeterminadas. No lo son sino miradas a nuestra luz, con arreglo a la horquilla de temporalizaciones de que somos capaces. Ahora bien, como dicha horquilla tampoco está enteramente fijada, hay como una vislumbre intermitente, en parpadeo, del ipse de ciertos sentidos (figura del parpadeo que encontrará Richir, más adelante, entre las características de la phantasia). Por eso, nos advierte Richir de que, refractaria a nuestra escala de temporalizaciones y espacializaciones, la auténtica fenomenalización del nada sino fenómeno (de su particularísimo ipse) se ofrece en parpadeo (en clignotement).

Por lo demás, y del lado de la subjetividad, que el hecho "negativo" de que esa horquilla esquemática propia, de cada sujeto, no esté fijada, corresponde al hecho "positivo" de lo que Richir llama "transpasibilidad": no sabemos lo que un cuerpo puede como decía Spinoza; no sabemos de qué o de cuánto somos capaces. Permitámonos en este punto citar un pasaje relativamente clarificador de las Méditations Phénoménologiques (1992), una de las obras más importantes de Richir, y cuyo subtítulo reza "Phénoménologie et phénoménologie du langage". En él empieza Richir refiriéndose a los términos de la filosofía, términos vivos y efectivos cuando, por debajo de ellos, corre vida fenomenológica, sentido haciéndose que se hace (y deshace) a distinta profundidad arquitectónica: 
"Todos estos términos son la indicación, hecha en lengua filosófica de problemas "por resolver", y que, en cierto sentido, jamás quedarán "resueltos" porque su "resolución" requiere tiempo, y tiempo según diversos ritmos a la vez, de entre los cuales, algunos, demasiado rápidos, suelen pasar inadvertidos, y en cambio otros, excesivamente lentos, requerirían, sin lugar a dudas, un tiempo de vida que excedería con mucho la duración de una vida humana"20

En realidad, en esta arquitectónica concreta de la experiencia en que se mueve el fenómeno de lenguaje, habremos de destacar al menos dos registros fundamentales (aunque puedan distinguirse muchos más). Tratemos pues de ver, ahora que ya sabemos a qué nos referimos con "fenómeno de lenguaje", qué ocurre exactamente cuando tratamos de decir algo, cuál es, en propio, la temporalización del "fenómeno de lenguaje".

\section{La temporalización del fenómeno de lenguaje y el sentido de una arquitectónica fenomenológica}

Ya habíamos señalado que el íncipit del fenómeno de lengua era algo así como un Einfall, una concreta indeterminación de carácter no arbitrario, una Sachlichkeit que aguarda ser desplegada, temporalizada, expresada y estabilizada. Todo ese proceso constituye una "fase de lenguaje". Así, de forma casi inmediata, noto haber captado algo. Esa captación ya está temporalmente trenzada. Efectivamente, la "fase de lenguaje" (cuyo inicio no puede, en rigor, fijarse) es ya siempre retención (aunque no husserliana pues no lo es de una proto-impresión, de una Urempfindung) de ese momento de iluminación (que nada tiene de puntual) que casi inmediatamente, dado lo insatisfactorio del contenido de mi presente, vira (revire) en protención, en la promesa de un sentido por desplegar que ya se ha captado; promesa que lo es, en realidad, de una fidelidad. Así, la promesa (o protención sui generis i.e. nunca protención de una protoimpresión) vira a su vez en recuerdo (o retención sui generis, i.e. nunca retención de una protoimpresión) de esa iluminación, de esa "compulsión de luz" a la que trató de ser fiel (Paul Celan hablaba de "Lichtzwang", de - así se ha traducido - "compulsión de luz"). Una vez más,

20 "Tous ces termes sont l'indication, nominalisante dans la langue de la philosophie, de problèmes « à résoudre », et qui, en un sens, ne seront jamais « résolus », parce que, en un autre sens, leur « résolution » demande du temps, et du temps selon plusieurs rythmes à la fois, dont certains, excessivement rapides, passent le plus souvent inaperçus, et dont d'autres, excessivement lents, demanderaient sans doute une durée de vie excédant largement la durée de la vie humaine.” RICHIR, M., Méditations Phénoménologiques, col. Krisis, ed. J. Millon, Grenoble, 1992. p. 379. 
hay que subrayar que esa fidelidad es retencional (fidelidad) y es, al tiempo protencional (promesa).

Lo que, en suma, se está diciendo también, es que el presente está, en esta incoación y desarrollo del fenómeno de lenguaje, como arrumbado, fuera de juego. Lo que sí sé es que lo "retenido" de la iluminación vira, al tiempo, en "protención" de su despliegue, revierte en la promesa (protención) de la fidelidad (retención) a lo que he captado (sin saber aún bien qué es lo que he captado; para saberlo habré de decirlo). Observamos pues cómo lo que está en juego en la viveza o Lebendigkeit de la experiencia del hacerse del sentido no es ni puede ser en ningún caso el contenido impresional o ingrediente de mi vivencia actual. Si lo fuera, si nos detuviéramos en ello, el proceso de Sinnbildung se frenaría para, finalmente, perderse y disolverse. Ocurre, muy al contrario, que, por encima o por debajo, aparte y en desajuste respecto del presente impresional, toda una plétora de retenciones y protenciones se entrecruza a una velocidad vertiginosa. El entrecruzamiento es tan súbito e inherente que el presente impresional está ausente del registro de temporalización en que se está tejiendo, en sus albores (son los momentos más inestables), la fase de lenguaje. Es así como, poco a poco, y en virtud de toda una serie más o menos violenta de revirajes o virazones ${ }^{21}$ ("revirements" dice Richir) de las protenciones en retenciones y viceversa, se va haciendo o urdiendo la fase de presencia (pero no de presente ni de presentes) de un fenómeno de lenguaje. ¿En qué sentido una fase de lenguaje también es una fase de presencia?

El proceso de apropiación de un sentido de algún modo ya sabido, la decantación y estabilización que esa apropiación supone, constituye, como ya hemos señalado, una fase de lenguaje; ahora bien, esa fase de lenguaje es también vigilia sobre ese despliegue. Por eso, una fase de lenguaje constituye, también, una fase de presencia. Digo bien fase "de presencia" y no "de presentes (continuos)" sencillamente porque lo que es "en presencia" no corresponde a un estricto continuo impresional. Antes bien requiere cierta proto-espacialización para que pueda tener lugar el juego de virazones de las retenciones en protenciones y de las protenciones en retenciones. Toda fase de lenguaje es, en suma, un determinado tipo de temporalización. ¿De qué tipo es pues esa temporalización?

La particular temporalización de la fase de lenguaje consiste, como hemos visto, en un trenzado no impresionalmente mediado entre protenciones y retenciones. Protenciones y retenciones sui generis - decíamos - pues su relación (de virazón mutua) es directa y no mediada por un presente, por un ahora. Son, directamente, retención de una protención (me acuerdo de

${ }^{21}$ En español, la palabra "virazón”, es un golpe de viento súbito; para ser más exactos, un cambio súbito en la dirección y (en la intensidad) del viento; es un término náutico. 
la promesa de un sentido) y protención de una retención (me propongo desplegar un sentido ya captado, la promesa de un recuerdo, de una fidelidad). Esto implica que el "ahora" de una fase de presencia no es impresional, no es "en presente" sino precisamente "en presencia". Dicho de otro modo: el "ahora" de una fase de lenguaje está proto-espacializado respecto de toda proto-impresión. Por eso es (y puede ser) directamente retentivo y protentivo, y configura una presencia, una vigilia proto-espacializada respecto del proceso mismo. Esta proto-espacialización es condición de posibilidad: la fase de lenguaje sólo puede desplegarse como fase de presencia y no de presentes. El sentido sólo puede vivir y elaborarse en la distancia de lo "en presencia" y gracias al entreveramiento no impresional entre retenciones y protenciones. Efectivamente, si el sentido tuviera que pasar de presente en presente sencillamente se perdería. Tiene necesariamente que estar más o menos adelantado y retrasado respecto de sí mismo o, si se quiere, respecto de un ahora proto-espacializado que no es un ahora protencional sino más bien ese trenzado entre avance y retraso y donde el grado de avance y de retraso no pueden fijarse. Son un desajuste hecho de avances y retrasos que se van, todo lo más, civilizando, auto-conteniéndose dentro de un esencial escaparse de sí insaturable por principio.

No quiere decirse con ello que desaparezca de la vida del sentido toda impresionalidad. Más bien se sostiene que, en esos primeros lances del sentido haciéndose, lo estrictamente impresional es ajeno a esa tejumbre entre retenciones y protenciones revirando las unas en las otras. El ahora impresional, en cambio, pertenece, sencillamente, a otro registro arquitectónico, el del "esquematismo de la repetición repitiéndose": el registro de los presentes, y donde el esquematismo del sentido haciéndose (esquematismo de lenguaje, esquematismo en presencia) es, literalmente, inviable: queda ahogado, sin vía de paso.

Recapitulemos para ahondar un punto más en la cuestión del "esquematismo". En el esquematismo de lenguaje, el desajuste (écart) entre retenciones y protenciones conforma esa presencia, esa vigilia (nunca de sobrevuelo, sino involucrada en el hacerse del sentido), ese intransitivo "asistir al" sentido que es, al tiempo, un transitivo "asistir el" sentido (como una partera asiste un nacimiento). La "fase de presencia" que dibuja toda "fase de lenguaje" no es sino un trenzado de fases originariamente adelantadas y retrasadas respecto de sí mismas. Ese movimiento que se adelanta y se retrasa respecto de sí mismo, y que pone a prueba las capacidades del sujeto, su arco de fenomenalización, es lo que Richir llama esquematización o esquematismo. El esquematismo tiene la particularidad de ser, a un tiempo, un movimiento progrediente y retrogrediente. No es un movimiento continuo. Tampoco, en rigor, discontinuo. No puede representarlo una línea. No puede representarse de modo fiable, sean cuantas sean las dimensiones del espacio de representación. Se trata de un movimiento que está en las antípodas de 
un movimiento continuo, está como atrasado y adelantado respecto de sí mismo, y lo está - adelantado y retrasado - a la vez. Se atrasa adelantándose y se adelanta atrasándose. De ahí que el "ahora" de dicho movimiento sea radicalmente inencontrable; sin que, por ello, dicho movimiento sea una pura dispersión. Efectivamente, como hemos sugerido más arriba en relación a esa indeterminación concreta que es el ipse del sentido, este movimiento, que responde, precisamente, a la fenomenalización de esas Sachlichkeiten, no es, por discontinuo y parcialmente auto-solapado que sea, pura disgregación. Precisamente por ello el esquematismo no es en absoluto asimilable, por caso, a la diseminación derridiana. Es, antes bien, lo que responde y reacciona a la configuración de concretudes arcaicas, de concretudes que no están a nuestra escala y a las cuales sólo podemos asistir ${ }^{22}$ en parpadeo. Ahora bien, quien habla de concreción o concretud, habla de una cierta cohesión, por arcaica que sea. Antes de habérnoslas con las concretudes del fenómeno de lenguaje, desarrollemos un punto más el movimiento de progradación y retrogradación de que parece estar hecho el esquematismo, y en virtud del cual se atraviesan y depositan, acrecientan y decrecen, las concretudes que el fenómeno de lenguaje atraviesa.

En el movimiento de dar sentido, mi pensar, mis "actos" de dar sentido, parecen desplazarse respecto de la pura actualidad, respecto de todo momento que pueda sancionar el significado de un decir "ahora" en sentido estricto (no en el sentido proto-espacializado antes mentado). Efectivamente, lo que, al decir "ahora", hallaría estricta referencia, es y sería una simple impresionalidad, perfectamente ajena a ese entretejimiento mutuo entre protenciones y retenciones que conforma la fase de presencia, lábil, frágil, metaestable, del fenómeno de lenguaje. El fenómeno de lenguaje está, digamos, originariamente desplazado, organizado de entrada en protenciones y retenciones. En protenciones que pasan a retención y retenciones que pasan a protención sin por ello atravesar el ahora; sin ser protenciones o retenciones de un ahora en sentido estricto, es decir, de un ahora impresivo o, si se quiere, de la proto-impresión que, en parte, conforma la Empfindung. Aunque esta "temporalización en fase" (que, repetimos, no es puro estallido, no es pura diseminación) está en las antípodas de la temporalización del flujo del tiempo inmanente (como flujo esencialmente continuo y radicado en torno a la proto-impresión) que describe Husserl en las Lecciones sobre la conciencia interna del tiempo (Hua X) de 1905, cumple señalar que el tipo de temporalización a que Richir apunta está en parte intuido o acariciado - como el propio Richir reconoce - por el propio Husserl en los Manuscritos de Bernau (Hua XXXIII).

22 En su doble sentido de "asistir a" en sentido intransitivo y "asistir" como "asistir (algo)" en sentido transitivo. 
Decisivo es, claro está, el tipo de ejemplos considerado. Uno de los problemas de las Lecciones de 1905, cuya genialidad, con todo, no ha de menoscabarse, estriba en que el fenómeno paradigmático de que se ocupa el análisis fenomenológico no es otro que el de un sonido monocorde que dura (un sonido sin ritmo ni melodía). Evidentemente, ese ejemplo sí admite un análisis en términos de presentes continuos protenidos y retenidos. No así la música ritmada y melódica y menos aún el hacerse de un sentido, la temporalización de esa búsqueda de un sentido. Cuando estoy tratando de captar una melodía, tengo que estar continuamente proteniendo y reteniendo $\mathrm{y}$, hasta cierto punto, poniendo entre paréntesis el presente impresional. Así, como sugiere el propio Husserl en los Manuscritos de Bernau, tiene que haber protención de las retenciones y retención de las protenciones. La actual Empfindung o Urempfindung en sentido literal existe, ciertamente, pero en otro registro de fenomenalización que no es el de la esquematización de la melodía misma. Lo que sea esa impresión no tiene mucho que ver con la música misma, con lo que se está de veras temporalizando.

Algo análogo sucede con todo sentido haciéndose. Si yo detengo el quehacer del sentido un momento y ausculto lo que es de mi presente impresional, nada tengo de relevante respecto del fenómeno en cuestión. Evidentemente, esto no es generalizable a todo tipo de fenómenos. Sólo a aquellos que ponen en juego determinado tipo de esquematismo. Así, en el caso de una mera percepción, de la percepción, pongamos por caso, de esta mesa que tengo enfrente, lo que estoy viviendo en presente en un determinado momento (por ejemplo la sensación de color y tacto de esta mesa) sí tiene relevancia para el sentido global (la percepción de una mesa), a pesar de que, claro está, haya que distinguir la inmanencia real de la inmanencia intencional. Ahora bien, los datos hiléticos que se ofrecen en inmanencia real sí ofrecen cierta plenificación, una genuina Füllung a la mención intencional (sin que esa Füllung constituya todo el proceso de Erfüllung propiamente dicho, y que compromete, claro está, aspectos genuinamente intencionales y no simplemente hiléticos). Y ello sucede porque esa mención intencional no es, precisamente, esquemática.

Esta relativa relevancia, este no desfasamiento o coalescencia de la impresionalidad de los presentes con determinados objetos también se da en otros actos o experiencias. En actos que, precisamente, no ponen en juego el tipo de esquematismo o registro de fenomenalización que sí entra en liza en los fenómenos de temporalización de un sentido (por ejemplo la escucha de una melodía, la comprensión de un poema y otro tipo de fenómenos de lenguaje). En dichos actos, planos por así decirlo, rige un esquematismo del continuo como continuo. Son actos que se temporalizan en presente y a los que resulta enteramente adecuada y no equívoca la denominación husserliana de "actos": son ellos mismos, efectivamente, actuales. Son, de hecho, del 
mismo tipo de actualidad que las impresiones presentes que los sustentan. Así pues, ejemplos en los que funciona ese esquematismo de la repetición (y temporalización según presentes) pueden ser ciertos afectos relativamente superficiales. Por ejemplo un puro dolor físico. Pero también pueden serlo afectos más "espirituales", lo cual manifiesta que la línea de demarcación de estos dos tipos de esquematismos y temporalizaciones ("en presencia" por un lado, "en presentes" por el otro) no coincide con la línea de demarcación entre lo físico o fisiológico y lo psíquico. Así, una ira intensa y superficial, una ira ciega, también se agotaría en cierta impresionalidad. No habría, en ella, esquematismo de lenguaje. Lo mismo podría decirse, hasta cierto punto, de una obsesión, que parece teñir la vida de un continuo, el de un determinado color que no permite esa holgura de proto-espacialización necesaria al despliegue de un sentido. De ahí que toda obsesión sea extraordinariamente empobrecedora, pobre en fenomenalizaciones. No hay sino la obsesión misma, según un esquematismo de la repetición repitiéndose. Toda presencia a queda aplastada en el ser-presente, en el estar siendo presente tal impresión, y toda holgura de vigilia se tiñe de esa impresión. Sea como fuere, y salvando las distancias analíticas entre ellos, son, todos estos, fenómenos cuyo ahora, en su estricto contenido impresional, sí parece tener que ver con el todo del fenómeno.

No es eso lo que ocurre con otros fenómenos que, necesariamente, requieren la puesta en juego de otro registro de fenomenalización, el del esquematismo llamado "de lenguaje", y cuya temporalización es en presencia pero sin presente asignable. Ahora bien, esto no significa que no se trate de fenómenos concretos: he ahí, manifiesto una vez más, el rigor de la fenomenología, y que no es otro el de su ausencia de supuestos, y en virtud del cual cabe sostener que la fenomenología es auténtico empirismo, es decir, un empirismo que no prejuzga el tipo de empiricidad o empiria con que se encuentra y que, así, termina abriendo espectralmente el sentido de la facticidad o de la concretud en general.

Efectivamente, en ciertos registros de fenomenalización, lo concreto resulta no ser del tipo del presente impresional. Es más: tiene que no serlo presente - para poder fenomenalizar determinadas concretudes. Ya habíamos señalado que el supuesto ahora impresional, el que satura un determinado presente de la escucha melódica, nada nos dice sobre la melodía. Antes bien, detiene, embota y satura el fenómeno de captación de la melodía y el esquematismo de lenguaje que dicha captación requiere, a saber, un esquematismo originariamente desfasado, en avance y retraso respecto de sí, y que no puede compadecerse con el presente impresional. Tampoco el ahora impresional de las afecciones más profundas nos dice nada de las mismas. Incluso puede resultar engañoso. La temporalización de éstas es otra, más profunda, tejida 
entre horizontes afectivos de pasado y de futuro que no pasan por el presente (y que, sin embargo, contribuyen a la concreción de la vida, de lo que cabe llamar su presencia, o su "ahora" pero en sentido amplio).

Pues bien, otro tanto sucede con los fenómenos de la phantasia ${ }^{23}$ y con su particular temporalización, lo que explica el enorme interés que Richir ha atribuido a este capítulo de la fenomenología husserliana ${ }^{24}$. Si yo me pierdo en una phantasia y, de repente, me pregunto cuál es el contenido de un determinado ahora fantaseante, el "contenido ingrediente" del acto, nada tengo. Nada que tenga cierta relación con la experiencia de phantasia que estaba viviendo o quasi-viviendo. Los supuestos phantasmata, correspondientes, en la phantasia, de las Empfindungen, se me escapan entre los dedos. O, si se quiere, lo que recojo, nada tiene que ver con la viveza de la phantasia tal y como se está temporalizando en y para mi conciencia. Lo subjetivo que acompaña a una determinada Phantasieerscheinung también es originariamente no presente. Más bien radica en un Phantasieich (con su Phantasieleib), originariamente desplazados de mi yo y de mi cuerpo actualmente fantaseantes. No son estos últimos los que están de veras involucrados en la escena que flota delante de mí, en la phantasia (la Phantasieerscheinung que schwebt mir vor, dice Husserl).

Sin embargo, desde el momento en que reconozco que hay varios registros de experiencia con varios registros de temporalización, y que todos son fungierend a la vez, que todos funcionan a la vez en la experiencia de dar sentido, entonces reconozco que algo fenomenológicamente concreto no tiene por qué ser algo que se dé aquí y ahora, en el modo del presente. A la concretud, incluso a la concretud aparentemente fisiológica, es esencial el concurso de ciertos horizontes de ausencia. Lo es tan pronto como esa concretud se revela con sentido, con un sentido necesitado de despliegue, en desajuste consigo mismo, y siendo, al tiempo, promesa y fidelidad. Acaso haya ciertas impresiones aparentemente fisiológicas y, sin embargo, intrínsecamente arquitectónicas, movilizantes o con-movedoras de varios registros de fenomenalización.

23 Siguiendo a Richir en esto, recuperamos el término griego para traducir el término alemán "Phantasie" porque "fantasía", en el español actual, está prácticamente en las antípodas de lo que Husserl quería decir con "Phantasie", más similar, en cambio, al griego phantasia.

${ }^{24}$ Cf. ALVES, Pedro. M. S., Fenomenología del tiempo y de la percepción, Biblioteca Nueva, Madrid, 2010. Traducción al español de Francisco Conde Soto. Se puede consultar con mucho provecho el magnífico capítulo que el profesor Alves dedica a estas cuestiones, titulado "La doctrina husserliana de los actos intuitivos sensibles y el tema de la conciencia del tiempo desde 1898 hasta 1911" e incluido en las pp. 127-186 de la citada obra. Por desgracia, no dispongo de la edición original, en lengua portuguesa. 
Un sabor fino, tenue, especial, nunca satura impresionalmente como sí lo haría un sabor empalagoso, exclusivamente fisiológico por así decirlo. El sabor fino, evocador, es más (y menos) que su presente, y acaso el arte de cierta cocina estribe en saber convocar, desde sabores que son determinadas invitaciones a una suerte de proto-esquematismo, ciertos horizontes de ausencia. Esos sabores habrán de generar como un desajuste respecto de su impresión gustativa, ser más y menos que su propia actualidad. Y, de hecho, al intentar captarlo, fijarlo, lo perdemos. El buen sabor sabe en coalescencia con sus horizontes de ausencia, su saber bien es consustancialmente lateral.

Exactamente igual sucede con un olor, y quizá sea un secreto nunca de veras aprendido (pues no hay técnica que lo enseñe) de todo buen perfumista. La concretud de la fragancia agradable o sugerente, de la fragancia profunda, nunca tiene la firmeza brutal de un ahora impresional, sino que parece sostenerse en algo muy sutil, en una evocación, en una de esas concretizaciones desde horizontes de ausencia. Lo mismo, en el tacto, ocurre con la leve caricia. La propiciada por otro cuerpo o por una simple brisa. Los fenómenos de sentido más vivaces, aquellos en los que de veras funciona un esquematismo de lenguaje (así se trate de sensaciones sentidas como aquellas a que hemos aludido), son aquellos para los que sería irrelevante lo que es la actualidad instantánea de la vida, lo que una suerte de corte transversal o muestra de lo actualmente sentido arrojase.

La posibilidad de una firme concretud del todo ajena al presente es especialmente patente en otro caso que bien pudiéramos añadir a los anteriores. Se trata de la experiencia del otro, y de la Einfühlung (acto muy complejo en el se conjugan varios tipos de acto, fundamentalmente la Wahrnehmung y la Phantasie). Así, por caso, la apresentación de la vida del otro es una experiencia directa (aunque fundada en una percepción). Es el directo sentir que hay vida ahí, animando el cuerpo del otro, o, más bien, vida directamente entreverada con su cuerpo. Ahora bien, la apresentación de la vida del otro, con ser una Phantasie, nunca es una Bildbewusstsein, una conciencia de imagen, como tampoco - aunque Husserl parezca seguir en ocasiones esa vía (que terminará criticando como absolutamente errada) - algún tipo de razonamiento analogizante (un Analogieschluss). Hay una concreta perzeptive Phantasie de la ipseidad del otro, de su irremplazable singularidad y donde la mera Wahrnehmung del cuerpo del otro ya no funciona como acto fundante sobre el que se asienta una supuesta Phantasie. En la Einfühlung de la ipseidad del otro no hay tanto Wahrnehmung de su cuerpo cuanto Perzeption directamente entreverada con una Phantasie, y donde lo "percibido (en el sentido de perzipiert, no de wahrgenommen)" en phantasia no es en absoluto asimilable a un Bildsujet. Lo "percibido" por phantasia "perceptiva" es una singularidad infigurable y no dada "en presente". Con todo, y a pesar de esta apariencia de esencial volatilidad, se trata de algo manifiesto, firme- 
mente notado (por imposible de figurar que sea): notamos inmediatamente, por ejemplo al volver a ver a un antiguo amigo que no habíamos visto desde hace años, cómo se hace "presente" (pero en el sentido de abrirse espacio, hacerse infigurablemente patente), de nuevo, su inconfundible singularidad.

Algo parecido y, si cabe, más enigmático aún, sucede con los personajes de novela. Sucede sólo, claro está, con los personajes logrados, con los personajes literariamente conseguidos, es decir, con aquellos personajes que súbitamente van tomando cuerpo al punto de ganar una enorme concretud que acaba imponiéndose al propio autor, y ello al extremo de que, llegado determinado momento (por lo demás insituable), el autor ya no es libre de hacer lo que quiera con el personaje. Pues bien, el lector (dejemos a un lado el caso, más complejo, del autor) siente por Einfühlung esos personajes ${ }^{25}$, su singularidad. La siente sin hacer falta que imagine, en una suerte de conciencia de imagen interna, esos personajes ${ }^{26}$. De ahí que pueda uno decir, sin haber necesitado imaginarme nunca un personaje de novela, pero habiéndolo sentido en su concretud, que tal o cual película es una mala adaptación... sin por ello estar necesariamente en medida de proponer una mejor posibilidad de figuración. Todo lo más una menos mala. En realidad, el registro de infigurabilidad de las concretudes que están en juego en esa experiencia de phantasia que es leer una novela condena a toda adaptación cinematográfica a resultar, en el fondo, insatisfactoria. Representar esas phantasiai es una forma de traer a un nivel arquitectónico (el de la percepción o la conciencia de imagen, con una temporalización en presente) lo que pertenece a otro registro de fenomenalización, el propio de la phantasia, y que requiere una temporalización en presencia (sin presente asignable).

Insistamos, a modo de conclusión, en el profundo vuelco que el punto de vista arquitectónico introduce en fenomenología. Vuelco en loor del "empirismo" fenomenológico. Si, como el análisis fenomenológico lo pretende, quiere uno aproximarse a la génesis de un sentido, no se puede, para determinados casos, para determinadas experiencias y "objetos" de experiencia, fiar esa manifestación o re-concretización a una re(con)ducción al presente vivo. Ciertos órdenes y "objetos" de experiencia como los fenómenos de lenguaje (en su amplísimo alcance) nos enseñan que el presente vivo es, más bien, un

${ }^{25}$ Lo que en cierto modo manifiesta, una vez más, que la Phantasie es más esencial a la Einfühlung que la Wahrnehmung; o, mejor dicho, que se basa en lo que de Perzeption tiene la Wahrnehmung.

26 Tener que hacerlo, que esforzarse en ello, es, antes bien, signo de que el personaje no está bien confeccionado por el novelista. Eso mismo sugiere Husserl cuando introduce, en el texto $\mathrm{n}^{\circ} 18$ de Hua XXIII en el contexto de un análisis fenomenológico del teatro, el concepto de perzeptive Phantasie. 
problema, que su masividad, su indistinta evidencia, representa una auténtica amenaza para la sutileza multiestratificada del fenómeno. El presente puede ser un factor de aplastamiento de la espectralidad en que se mueve la vida transcendental. La fenomenalización directa y sin distancia del presente vivo no siempre me acerca más al sentido de una experiencia. La masividad del presente puede ser la losa que aplaste la sutileza de registros de fenomenalización celados en un fenómeno. La fenomenología arquitectónica elaborada por Marc Richir, contrariamente, por ejemplo, a la de Michel Henry (que representa cierta recepción de Husserl), instila una desconfianza respecto del prestigio del presente y de la autoafección. Ahora bien, la desconfianza en el prestigio del presente tampoco conduce la fenomenología a echarse en manos de esa renuncia al sentido de la fenomenología llamada "hermenéutica", y menos aún en manos de ese ultra-semiotismo denominado "deconstrucción". Hay, como siempre ha ocurrido en fenomenología, una ampliación del concepto de experiencia. Ampliación que, en el caso de la propuesta de Richir, se produce en los términos de una multiestratificación de los registros de fenomenalización. 
